\title{
Rancang Bangun Robot 6WD Dengan Sensor Gas TGS2600 Menggunakan Metode Wall Following Berbasis Arduino Mega 2560
}

\author{
I Made Arya Budhana $^{1}$, Ida Bagus Alit Swamardika ${ }^{2}$, Yoga Divayana ${ }^{3}$
}

\begin{abstract}
The current development of technology especially in the field Robotics is very rapid, one form of the robotics technology application that is closely related to the control system is a wheel mobile robot. Several methods can be performed to distribute natural gas is using the pipeline. Distribution of natural gas using pipelines often have constraints leak incidents . They are caused by pipelines age which are too old to operate safely. To facilitate monitoring of the gas pipeline under the ground is used 6WD (Six-wheel drive) robot which has 6 wheels and actuators on each wheel to overcome the severe terrain. The movement of the $6 \mathrm{WD}$ robot using ultrasonic modul sensor SRF HC-SR04, this method is called wall following. Figaro TGS gas sensor type is used to detect a gas leak in the pipes. In addition, the robot is also equipped with a camera to send pictures of pipe damage to the user in order to repairs immediately.

Arduino Mega 2560 is used as a brain on 6WD robot, it is responsible to process the incoming data and gives instruction on robot $6 W D$. Data transmission from 6WD robot to the user include gas sensors data, compass sensor data, proximity sensor data and image of pipeline damage. All data can be look at GCS (Ground Control Station).
\end{abstract}

Intisari- Perkembangan teknologi khususnya dibidang robotika saat ini sangat pesat, Salah satu bentuk aplikasi dari teknologi robotika yang erat kaitannya dengan sistem kontrol adalah wheel mobile robot. Beberapa metode dapat dilakukan untuk mendistribusikan gas alam salah satunya dengan pipa. Distribusi gas alam dengan menggunakan pipa sering mengalami kendala kebocoran yang disebabkan usia dari pipa distribusi yang sudah cukup tua. Untuk mempermudah pemantauan pipa gas yang berada di bawah tanah digunakan robot 6 WD (wheel drive) yang memiliki 6 roda dan penggerak pada setiap rodanya untuk mengatasi medan yang berat. Pergerakan dari robot 6 WD mengacu pada sensor ultrasonik SRF HCSR04, metode ini dinamakan wall following. Sensor gas tipe TGS dari figaro dimanfaatkan untuk mengetahui adanya kebocoran gas pada pipa atau tidak. Selain itu, robot ini juga dilengkapi dengan kamera untuk mengirim

${ }^{1}$ Mahasiswa, Jurusan Teknik Elektro dan Komputer Fakultas Teknik Universitas Udayana, Jln. Kampus Bukit Jimbaran 80361 INDONESIA (telp: 0361-703315; fax: 0361-4321; e-mail: aryabudhana60@gmail.com)

2, ${ }^{3}$ Dosen, Jurusan Teknik Elektro dan Komputer Fakultas Teknik Universitas Udayana, Jln. Jalan Kampus Bukit Jimbaran 80361 INDONESIA (telp: 0361-703315; fax: 0361-4321; e-mail: 2alitbbc@yahoo.com,3yogadivayana@gmail.com

I Made Arya Budhana: Rancang Bangun Robot 6WD... gambar kerusakan pipa pada user agar dapat segera dilakukan perbaikan.

Arduino Mega 2560 digunakan sebagai otak pada robot 6 WD yang bertugas untuk mengolah data yang masuk dan memberikan instruksi pada robot $6 \mathrm{WD}$. Pengiriman data dari robot 6 WD pada pengguna meliputi, data sensor gas, data sensor kompas, data sensor jarak dan gambar kerusakan pada pipa. Seluruh data dapat dilihat pada GCS (Ground Control Station).

Kata Kunci- 6 WD, Pipa gas, Wall following, Arduino Mega 2560, GCS

\section{Pendahuluan}

Perkembangan teknologi khususnya dibidang robotika saat ini sangat pesat, perkembangan dapat dilihat dari banyaknya penerapan teknologi robotika menggunakan sistem kontrol dan kecerdasan buatan dalam bidang industri, pendidikan, maupun kehidupan sehari-hari. Salah satu bentuk penerapan dari teknologi robotika yang erat kaitannya dengan sistem kontrol adalah wheel mobile robot. Beberapa metode dapat dilakukan untuk mendistribusikan gas alam agar menghemat biaya pendistribusian gas, salah satunya dengan pipa. Distribusi gas alam dengan menggunakan pipa sering mengalami kendala kebocoran yang disebabkan usia pipa distribusi yang sudah cukup tua. Kebocoran gas alam dalam jumlah besar dapat mengakibatkan pemanasan global yang memiliki efek 25 kali lebih kuat dibandingkan gas karbon dioksida [1].

Pada skripsi ini akan dibuat sebuah robot 6WD (Wheel Drive) yang akan mendeteksi kebocoran pipa gas alam yang ada pada gorong-gorong menggunakan sensor gas TGS 2600 dan pergerakan robot ini dijalankan secara otomatis dengan sensor ultrasonik menggunakan metode wall following berbasis mikrokontroller arduino mega 2560. Pada alat ini juga terdapat kamera yang akan menunjukkan kebocoran yang terjadi pada pipa distribusi gas alam. Semua data yang diperoleh dari robot akan dikirim melalui radio dan ditampilkan serta divisualisasikan dengan interface yang ada pada komputer atau laptop.

\section{KAJIAN PUSTAKA}

\section{A. Gas Alam}

Gas alam merupakan suatu campuran yang mudah terbakar yang tersusun atas gas-gas hidrokarbon, yang terutama terdiri dari metana. Gas alam juga dapat mengandung etana, propana, butana, pentana, dan juga gas-gas yang mengandung sulfur [2]. Komposisi pada gas alam dapat bervariasi. Pemaparan secara 
umum komposisi pada gas alam murni sebelum dilakukan pengolahan dapat dilihat pada Tabel 1.

TABEL I

KOMPOSISI GAS ALAM

\begin{tabular}{|c|c|c|}
\hline Methana & $\mathrm{CH}_{4}$ & $70-90 \%$ \\
\hline Ethana & $\mathrm{C}_{2} \mathrm{H}_{6}$ & \multirow{3}{*}{$0-20 \%$} \\
\hline Propana & $\mathrm{C}_{3} \mathrm{H}_{8}$ & \\
\hline Butana & $\mathrm{C}_{4} \mathrm{H}_{10}$ & \\
\hline Karbon Dioksida & $\mathrm{CO}_{2}$ & $0-8 \%$ \\
\hline Oksigen & $\mathrm{O}_{2}$ & $0-0.2 \%$ \\
\hline Nitrogen & $\mathrm{N}_{2}$ & $0-5 \%$ \\
\hline Hydrogen Sulphide & $\mathrm{H}_{2} \mathrm{~S}$ & $0-5 \%$ \\
\hline Rare Gas & $\begin{array}{l}\text { A, He, } \mathrm{Ne}, \\
\text { Xe }\end{array}$ & trace \\
\hline
\end{tabular}

\section{B. Sensor Gas TGS2600}

Figaro TGS 2600 adalah sensor utama yang digunakan dan merupakan sebuah sensor kimia atau sensor gas. Sensor ini mempunyai nilai resistansi yang akan berubah bila terkena gas dan juga memiliki sebuah pemanas (heater) yang digunakan untuk membersihkan ruangan sensor dari kontaminasi udara luar [3]. Struktur dari sensor gas TGS 2600 dapat dilihat pada Gambar 1. Output tegangan pada hambatan $\mathrm{R}_{\mathrm{L}}$ digunakan sebagai masukan pada mikroprosesor. Nilai resistansi $R_{L}$ dipilih agar konsumsi daya dari sensor di bawah batas $15 \mathrm{~mW}$, Nilai konsumsi daya akan meningkat pada waktu nilai resistansi sensor RS sama dengan resistansi RL [4]. Nilai konsumsi daya dapat dicari berdasarkan (1).

$P_{s}=\frac{\left(V_{c}-V_{o u t}\right)^{2}}{R_{S}}$

$R_{S}=\frac{V c \times R L}{V_{\text {out }}}-R L$

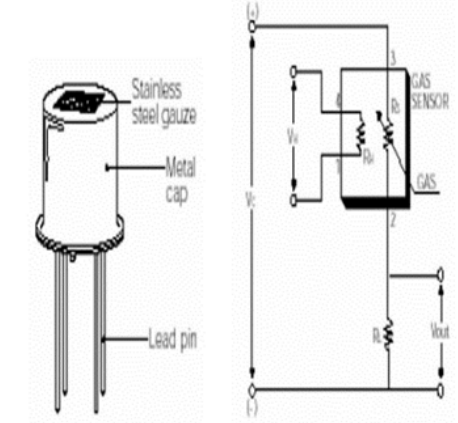

Gambar 1: Konfigurasi Pin Sensor TGS2600

\section{Arduino Mega 2560}

Arduino Mega 2560 adalah board mikrokontroler yang menggunakan Atmega2560 sebagai komponen utamanya. Memiliki 54 pin digital yang dapat digunakan sebagai Input maupun output. Arduino memiliki software sendiri untuk pemrograman dengan berbasis bahasa C yang bernama Arduino IDE. Software tersebut telah dilengkapi dengan library yang dapat mempermudah pengguna untuk melakukan pemrograman pada board arduino.

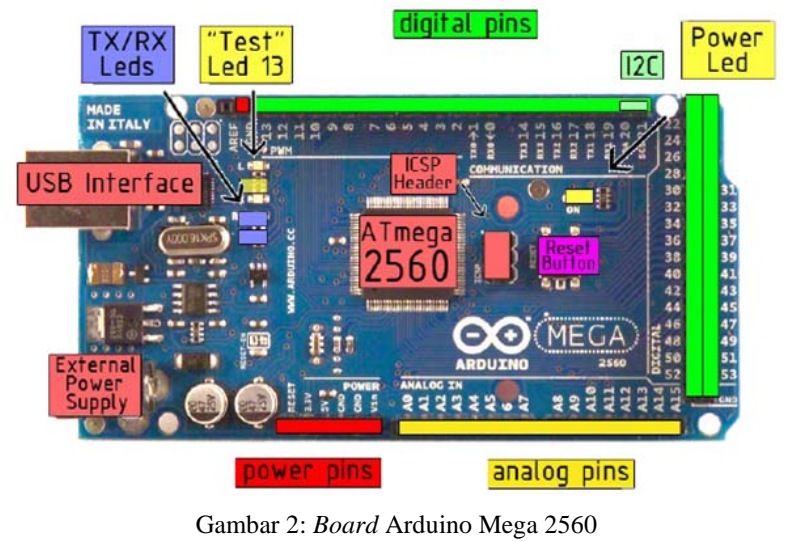

\section{Radio Telemetry HMTRP (RCTimer $433 \mathrm{MHz}$ )}

Radio Telemetry RCTimer sistem dasarnya menggunakan 3DR Radio System dan 100\% kompatibel. Radio ini dirancang open source sebagai pengganti radio xbee dengan frekuensi berbeda, menawarkan harga yang lebih murah, jangkauan yang lebih panjang. Menggunakan frekuensi 433 Mhz. Radio ini menyediakan saluran full duplex menggunakan modul HopeRF HM-TRP yang di modifikasi. Interface yang dapat terhubung menggunakan tegangan 5 Volt TTL serial atau Serial USB FTDI.

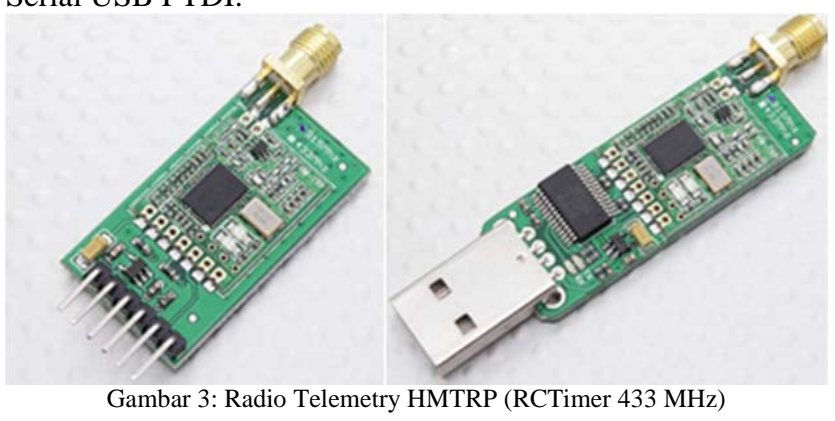

\section{E. Sensor Ultrasonik HC-SR04}

Sensor HC-SR04 adalah sensor yang dapat mengukur jarak menggunakan gelombang ultrasonik. Prinsip kerja sensor ini mirip dengan radar ultrasonik. Gelombang ultrasonik yang dipancarkan dan dipantulkan diterima oleh receiver ultrasonik. Jarak antara waktu pancar dan waktu terima adalah representasi dari jarak objek [5]. Lebar pulsa High (tIN) akan sesuai dengan lama waktu tempuh gelombang ultrasonik untuk 2x jarak ukur dengan obyek. Sehingga jarak dapat ditentukan menggunakan (3).

$$
\operatorname{Jarak}=\frac{t_{I N}(s) \times 344 \mathrm{~m} / \mathrm{s}}{2}
$$

Pada Sensor HC-SR04 pin trigger dan echo diletakkan terpisah. Sensor ini dapat mengukur jarak maksimal $400 \mathrm{~cm}$ dan jarak minimal $2 \mathrm{~cm}$. Selain itu sensor HC-SR04 memiliki sudut deteksi terbaik pada $15^{\circ}$, dengan tegangan kerja 5 Volt DC [6]. 


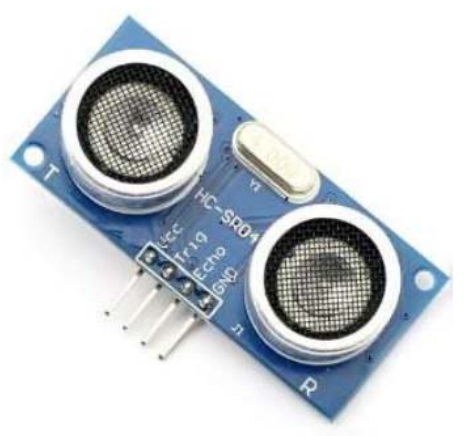

Gambar 4: Sensor Ultrasonik HC-SR04

\section{F. Modul Kompas CMPS03}

Kompas CMPS03 berukuran 4 x $4 \mathrm{~cm}$ ini menggunakan sensor medan magnet Philips KMZ51 yang cukup sensitif untuk mendeteksi medan magnet bumi. Kompas digital ini memiliki tegangan kerja 5 VDC dan konsumsi arus sebesar 15 mA. Pada CMPS03, arah mata angin ditunjukkan dalam bentuk derajat yaitu : Utara $\left(0^{\circ}\right)$, Timur $\left(90^{\circ}\right)$, Selatan $\left(180^{\circ}\right)$, dan Barat $\left(270^{\circ}\right)$. Pada CMPS-03, lebar pulsa positif merepresentasikan sudut arah. Lebar pulsa bervariasi antara 1 ms $\left(0^{0}\right)$ sampai $36.99 \mathrm{~ms}\left(359.9^{0}\right)$ terjadi perubahan $100 \mu \mathrm{s}$ setap derajatnya . [7].

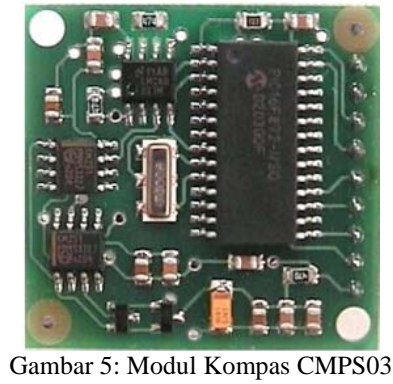

G. Modul H-Bridbge VNH3SP30-E(Embedded Module Series) Rangkaian $H$-bridge adalah rangkaian untuk mengemudikan motor DC yang menghasilkan keluaran dengan putaran motor yang dapat berputar searah jarum jam CW (clock wise), maupun berlawanan dengan arah jarum jam CCW (counter clock wise). Pada modul ini menggunakan $\mathrm{H}$ Bridge berbasis VNH3SP30-E (Automotive fully integrated $H$ bridge motor driver), yang dirancang untuk menghasilkan 2 arah dengan arus kontinyu sampai dengan 30 A pada rentang tegangan 5,5 Volt sampai 36 Volt. Selain itu modul ini dilengkapi dengan rangkaian sensor arus beban yang dapat digunakan sebagai feedback ke pengendali.

\section{H. Microsoft Visual C\#}

Bahasa pemrograman C\# merupakan bahasa pemrograman yang dikembangkan oleh perusahaan ternama Microsoft dengan proses pengembangan yang dipimpin oleh Anders Hejlsberg. Karena dikembangkan oleh perusahaan yang sama dengan pengembang .NET, maka bahasa pemrograman C\# menjadi bahasa pemrograman yang diintegrasikan sepenuhnya dengan library .NET. Kelebihan bahasa pemrograman C\# ini akan sangat menguntungkan para developer. Para developer akan dapat mengakses berbagai macam dukungan dan

I Made Arya Budhana: Rancang Bangun Robot 6WD...

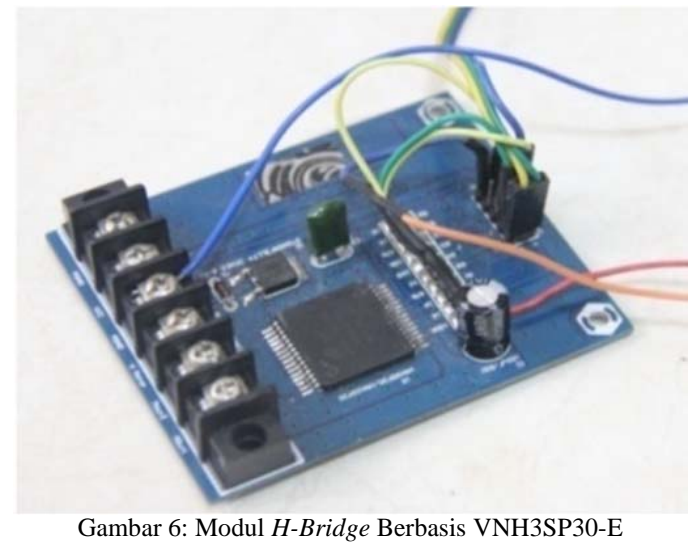

fungsionalitas yang disediakan oleh repository dari .NET. Para developer akan dapat mengembangkan aplikasi yang berjalan di Windows dengan sangat baik. [8].

\section{Metode Wall Following}

Metode wall following merupakan suatu algoritma untuk menyediakan orientasi navigasi kepada robot dengan menyusuri dinding. Salah satu keuntungannya adalah tidak perlu adanya garis penuntun ataupun suatu tanda khusus sebagai arahan bagi robot [9]. Cara kerjanya adalah dengan mengatur jarak dinding dengan robot tetap konstan. Bila terjadi perubahan, maka robot akan bergerak untuk kemudian menyesuaikan jarak lagi. Proses ini akan dilakukan secara berulang-ulang [10].

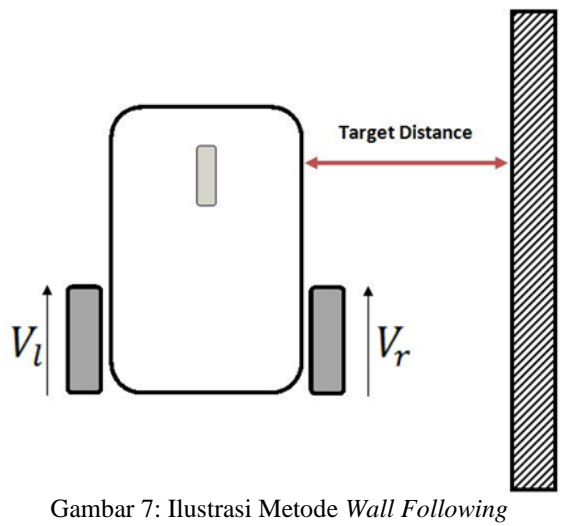

\section{Metode PERANCANGAN Sistem}

\section{A. Perancangan Hardware}

Dalam perancangan robot 6WD menggunakan sensor gas TGS2600 dengan metode wall following Berbasis Arduino Mega2560 ini terdiri dari dua buah bagian yaitu robot 6WD dan komputer yang didalamnya terdapat interface Ground Control Station (GCS).

p-ISSN:1693 - 2951; e-ISSN: 2503-2372 


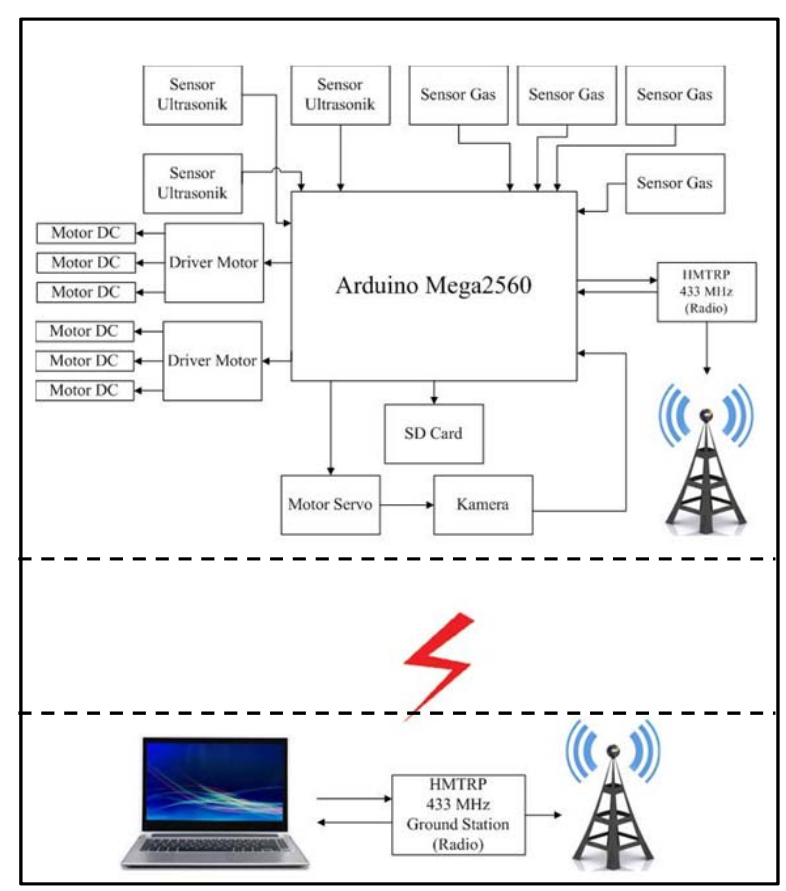

Gambar 8: Blok Diagram Perangkat Keras

\section{B. Perancangan Rangkaian Elektronika}

Perancangan bagian elektronika yaitu berupa pembuatan skema rangkaian dan pembuatan lay out dengan menggunakan software eagle 7.2 serta melakukan penctekan pada PCB (Printed Circuit Board).

\section{Perancangan Interface}

Perangkat lunak pada GCS adalah sebuah antarmuka (interface) yang digunakan untuk kontrol robot 6WD. Selain untuk kontrol robot, antarmuka GCS juga berfungsi sebagai output data sensor dari robot 6WD yang dapat memberikan visualisasi keadaan robot 6WD. Pada GCS, operator dapat memantau jarak antara dinding dengan robot, adanya kebocoran gas atau tidak, dan dapat mengambil gambar kebocoran pipa gas.

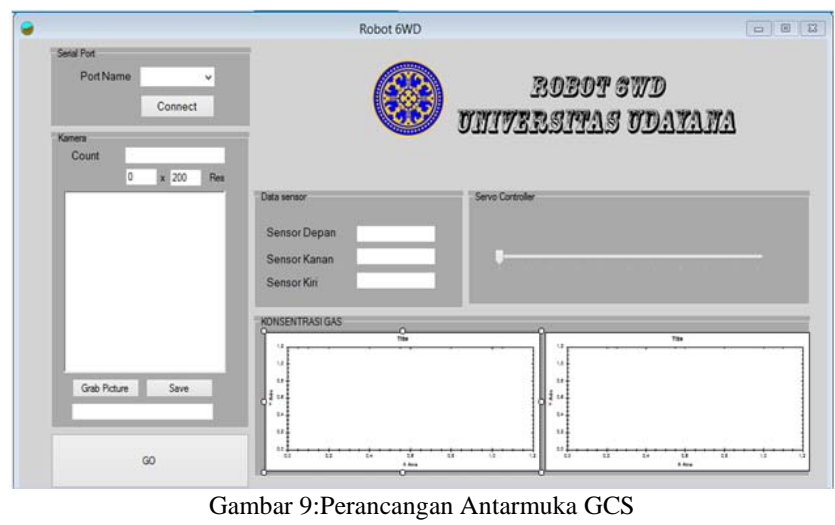

ISSN $1693-2951$

\section{Diagram Alir Sistem pada Robot 6WD}

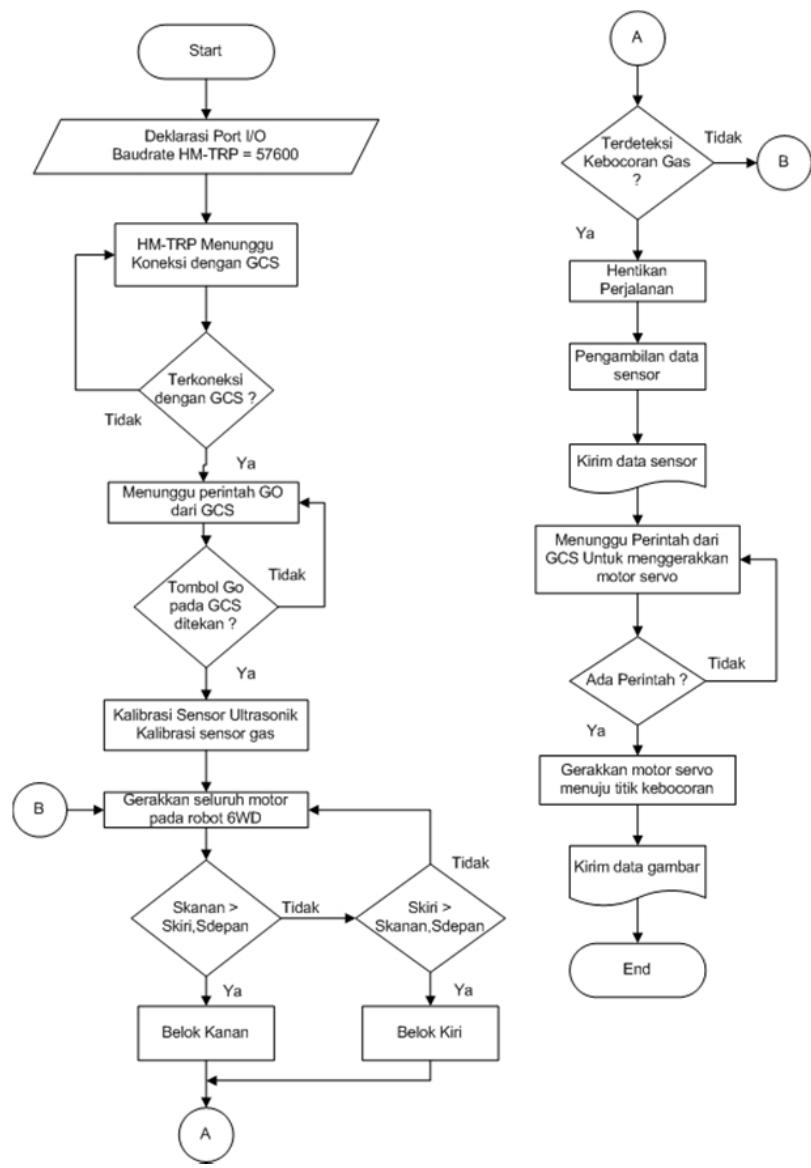

Gambar 10: Diagram Alir Robot 6WD

Dari diagram alir software robot 6WD dimulai dari pendeklarasian port input dan output yang akan digunakan, kemudian mendeklarasikan baudrate dari masing masing Tx $\mathrm{Rx}$ yang digunakan agar data yang dikirim maupun yang diterima dapat diterjemahkan. Kemudian robot 6WD menunggu perintah GO dari GCS. Setelah menekan tombol GO pada GCS, maka air station akan mengkalibrasi sensor ultrasonik bagian depan, bagian samping kiri, dan bagian samping kanan. Setelah data jarak robot 6WD dengan dinding terbaca, maka robot akan mulai bergerak, jika nilai sensor kanan lebih besar daripada sensor depan dan sensor kiri, maka robot akan bergerak ke kanan. Jika nilai sensor kiri lebih besar daripada sensor kanan dan sensor depan, maka robot akan bergerak ke kiri. Begitu terus hingga robot dapat berjalan dengan lurus pada suatu lorong. Pada saat terdeteksi adanya kebocoran gas, maka robot akan mengambil sebuah data dan mengirimkannya ke GCS, dari data yang ditampilkan pada GCS dapat diketahui sensor mana yang mendeteksi adanya kebocoran. Operator melalui GCS menggerakkan motor servo ke titik terdeteksinya kebocoran sehingga bisa dilakukan tindakan pengamanan dan perbaikan dari kebocoran pipa distribusi gas alam tersebut. 


\section{HASIL DAN PEMBAHASAN}

\section{A. Realisasi Hasil Perancangan}

Realisasi perancangan perangkat keras rancang bangun robot 6WD menggunakan sensor gas TGS2600 dengan metode wall following berbasis arduino mega2560 bisa dilihat pada Gambar 11:

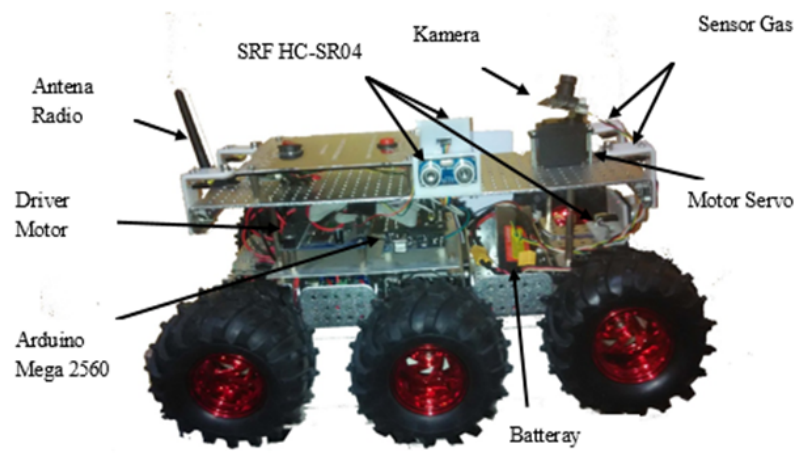

Gambar 11: Realisasi Robot 6WD

\section{B. Pengujian dan Pembahasan Sensor Gas TGS2600}

Sensor gas TGS2600 merupakan sebuah sensor yang dapat mendeteksi adanya kebocoran gas butana. Pengujian ini bertujuan untuk mengetahui sensor gas telah berfungsi atau tidak. Blok diagram dari arduino dengan input sensor gas dapat dilihat pada Gambar 12:

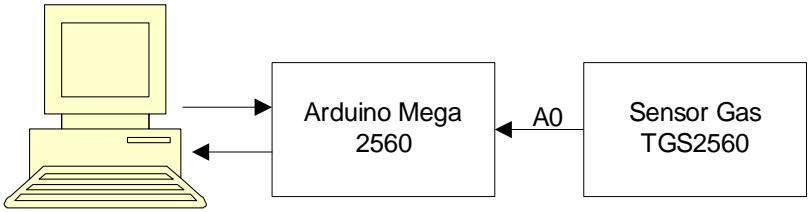

Gambar 12: Blok Pengujian Sensor Gas TGS2600

Adapun penggalan listing program dari sensor gas untuk mengetahui nilai ADC saat adanya kebocoran gas butana adalah sebagai berikut :

int $\mathrm{S} 1=\mathrm{AO}$;

int ADC;

void setup() \{

Serial.begin (57600):

pinMode (Sensor, INPUT); $\}$

void $\operatorname{loop}()$ \{

$\mathrm{ADC}=$ analogRead (Sensor)

Serial.print (ADC);

delay $(1000) ;\}$

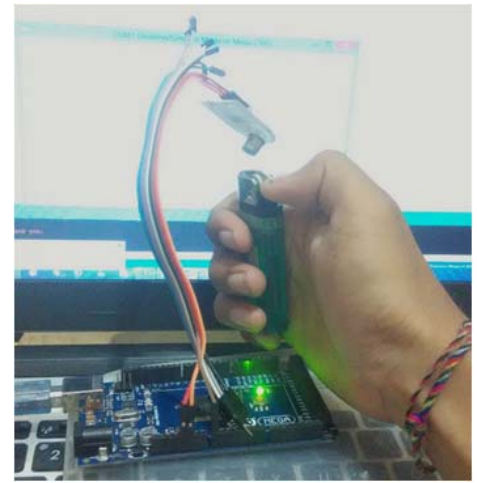

Gambar 13: Pengujian Sensor Gas TGS2600

I Made Arya Budhana: Rancang Bangun Robot 6WD...
Selain untuk mengetahui sensor sudah dapat mendeteksi adanya kebocoran gas, selanjutnya dilakukan pengukuran tegangan pada keluaran sensor, guna mengetahui perubahan resistansi sensor terhadap waktu pengujian. Perhitungan resistansi sensor TGS2600 dapat dilakukan dengan mengacu pada (2).

TABEL II

HASIL PERHITUNGAN RESISTANSI SENSOR GAS

\begin{tabular}{|c|l|c|c|}
\hline No & \multicolumn{1}{|c|}{ Pengukuran } & $\begin{array}{c}\text { Tegangan } \\
\text { Keluar } \\
\text { (Volt) }\end{array}$ & $\begin{array}{c}\text { Resistansi } \\
\text { Sensor } \\
\text { (Ohm) }\end{array}$ \\
\hline 1 & Tegangan saat normal & 0,228 & 21929,8 \\
\hline 2 & $\begin{array}{l}\text { Tegangan saat mendeteksi } \\
\text { perubahan gas }\end{array}$ & 1,327 & 3767,9 \\
\hline 3 & Tegangan saat nilai puncak & 3,878 & 1289,3 \\
\hline
\end{tabular}

Data pada Tabel II menunjukkan cara kerja dari sensor gas TGS2600 bahwa saat sensor mendeteksi kebocoran gas, maka resistansi sensor akan menurun dan menyebabkan tegangan keluaran naik.

\section{Pengujian dan Pembahasan Sensor HC-SR04}

Pengujian dari sensor ultrasonik bertujuan untuk mengetahui tingkat ketelitian dari sensor ultrasonik HC-SR04 untuk mengukur suatu jarak. Metode pengujian disini dilakukan dengan cara membandingkan hasil pengukuran jarak dengan sensor ultrasonik HC-SR04 dan dengan menggunakan sebuah mistar. Berikut adalah penggalan listing program untuk sensor SRF HC-SR04.

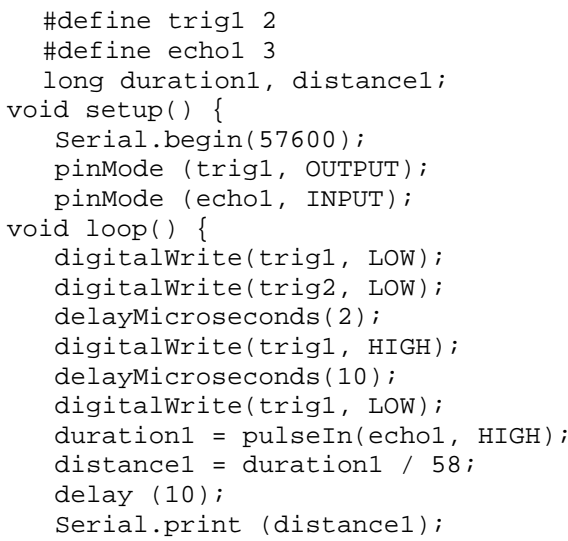

Gambar 14 merupakan foto pengujian akurasi jarak sensor ultrasonik HC-SR04. Data hasil pengujian dapat dilihat pada Tabel III untuk membandingkan hasil yang diperoleh sensor dan ditunjukkan oleh mistar.

Seperti yang sudah dijelaskan pada [3], sensor ultrasonik dengan tipe HC-SR04 akurasi sangat kurang untuk mengukur jarak kurang dari $2 \mathrm{~cm}$. Berdasarkan data pada Tabel 3 dapat dibuatkan grafik perbandingan antara jarak pada mistar dan jarak yang diperoleh sensor HC-SR04.

p-ISSN:1693 - 2951; e-ISSN: 2503-2372 


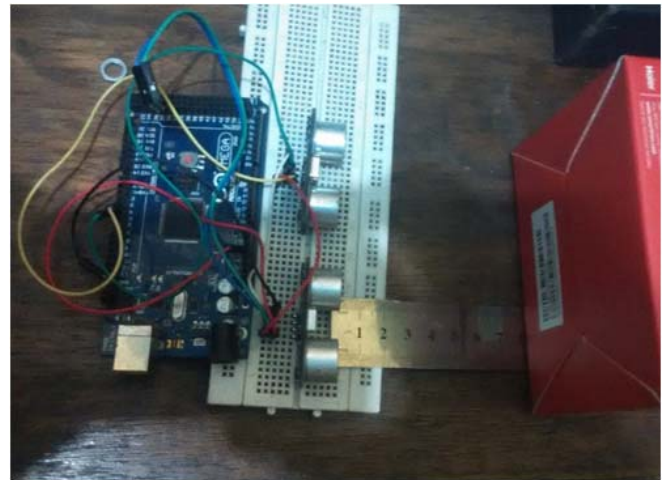

Gambar 14: Pengujian Sensor Ultrasonik HC-SR04

TABEL III

HASIL PENGUJIAN SENSOR HC-SR04

\begin{tabular}{|c|c|c|c|}
\hline No & $\begin{array}{c}\text { Jarak Mistar } \\
(\mathbf{c m})\end{array}$ & $\begin{array}{c}\text { Jarak Sensor } \\
(\mathbf{c m})\end{array}$ & $\begin{array}{c}\text { Waktu } \\
(\boldsymbol{\mu s})\end{array}$ \\
\hline 1 & 0 & 5 & 290 \\
\hline 2 & 1 & 4 & 232 \\
\hline 3 & 2 & 3 & 174 \\
\hline 4 & 3 & 3 & 174 \\
\hline 5 & 4 & 4 & 232 \\
\hline 6 & 5 & 6 & 290 \\
\hline 7 & 6 & 7 & 348 \\
\hline 8 & 7 & 8 & 406 \\
\hline 9 & 9 & 9 & 464 \\
\hline 10 & 10 & 10 & 522 \\
\hline 11 & & 580 \\
\hline
\end{tabular}

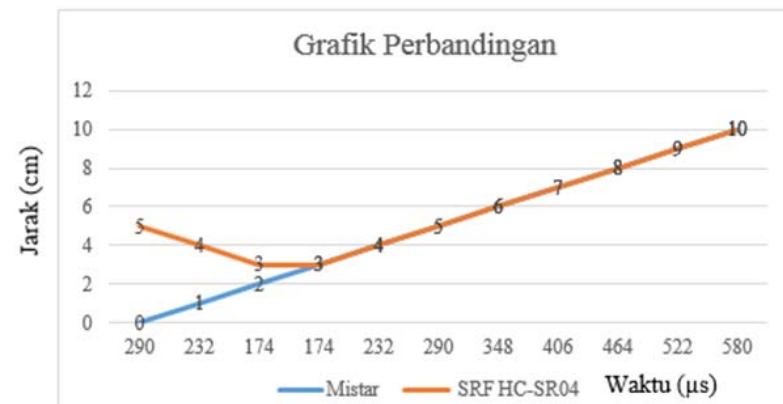

Gambar 15: Grafik Perbandingan Jarak HC-SR04 dengan Mistar

D. Pengujian Pembangkitan PWM dan Respon Driver Motor

Beberapa hal yang menjadi objek yang perlu di uji adalah pembangkitan PWM, duty cycle, dan perubahan output PWM dari arduino menjadi output pada driver motor secara linier atau tidak. Berikut blok diagram dari pengujian driver motor dapat dilihat pada Gambar 16:

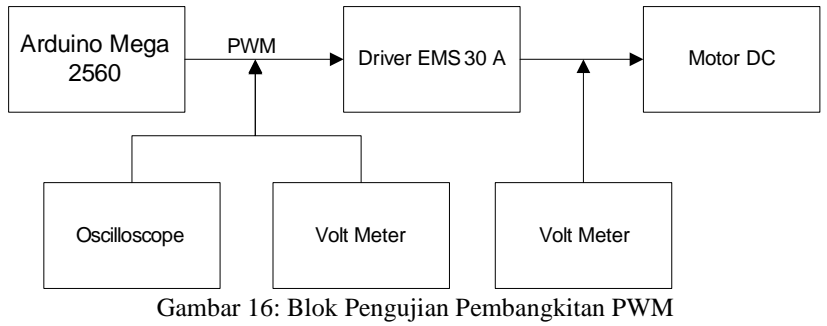

Data yang diperoleh dari pengujian pembangkitan PWM dapat dilihat pada Tabel IV.

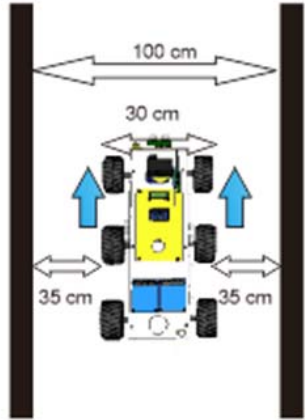

(a)

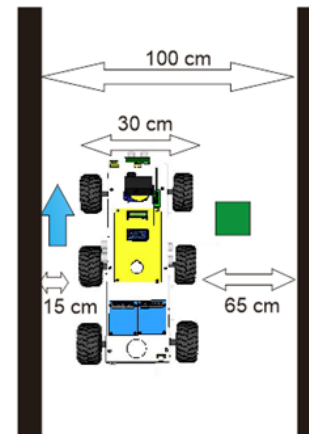

(c)

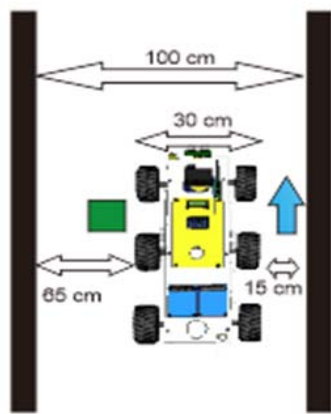

(b)

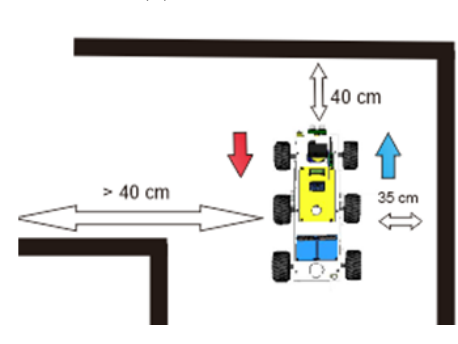

(e)

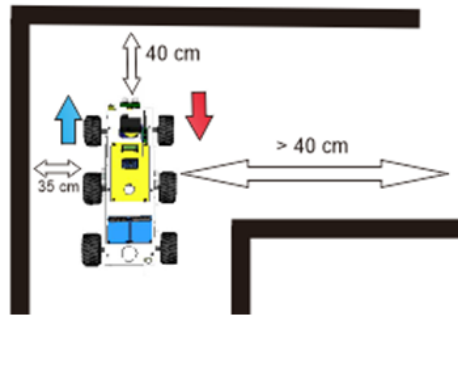

(d)

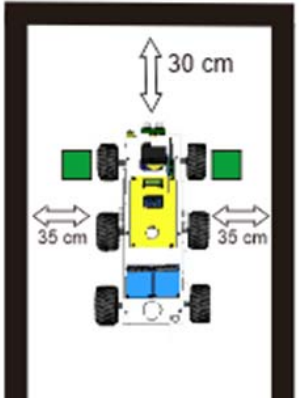

(f)
Gambar 17: Metode Wall Following

(a) Lurus, (b) Serong kiri, (c) Serong kanan, (d) Belok kiri (e) Belok Kanan, (f) Berhenti 
Majalah Ilmiah Teknologi Elektro, Vol. 17, No. 1,Januari -April 2018

DOI: https://doi.org/10.24843/MITE.2018.v17i01.P07

TABEL IV

Hasil Pengujian PEMBangKitan PWM

\begin{tabular}{|c|c|c|c|}
\hline $\begin{array}{c}\text { PWM } \\
\text { Input }\end{array}$ & $\begin{array}{c}\text { V }_{\text {In }} \text { Driver Motor } \\
\text { (Volt) }\end{array}$ & $\begin{array}{c}\text { Duty Cycle } \\
\text { (\%) }\end{array}$ & $\begin{array}{c}\text { Vout }_{\text {Oriver }} \\
\text { Motor (Volt) }\end{array}$ \\
\hline 50 & 0.95 & 19.6 & 5.95 \\
\hline 100 & 1.89 & 39.2 & 8.34 \\
\hline 150 & 2.86 & 58.8 & 9.35 \\
\hline 200 & 3.80 & 78.4 & 10.24 \\
\hline 250 & 4.74 & 98.0 & 10.61 \\
\hline 255 & 4.84 & 100 & 10.73 \\
\hline
\end{tabular}

Berdasarkan data pada Tabel IV dapat disimpulkan bahwa perubahan nilai dari PWM input mempengaruhi perubahan tegangan pada driver motor yang berarti perubahan ini linier.

\section{E. Pengujian Metode Wall Following}

Pengujian ini bertujuan untuk mengetahui respon dari robot saat berjalan menelusuri dinding. Robot akan berjalan menelusuri dinding dengan jarak terdekat pada bagian kanan dan kiri robot dengan dinding sesuai dengan algoritma pemrograman yang telah diberikan pada robot. Berikut adalah ilustrasi dari metode wall following yang telah dibuatkan untuk robot 6WD ini.

Dari Gambar 17 dapat dilihat beberapa ilustrasi metode wall following yang diterapkan pada robot 6WD. Berikut penjelasan dari kode yang ada pada gambar, tanda panah berwarna biru berarti bergerak maju, panah merah berarti bergerak mundur, dan kotak hijau berarti berhenti.

\section{F. Pengujian Fungsi Keseluruhan}

Setelah semua pengujian perbagian telah selesai, maka yang terakhir dilakukan adalah pengujian keseluruhan sistem dari robot 6WD dilengkapi dengan sensor gas TGS2600 menggunakan metode wall following yang dilakukan di gedung Student Center Universitas Udayana. Setelah melakukan pengujian data yang diperoleh akan dianalisa akurasi pembacaan arah, jarak, serta kebocoran gas.

Pengujian ini dilakukan untuk mengetahui keberhasilan dari penggabungan seluruh sistem yang digunakan pada robot 6WD. Sensor jarak dan sensor gas yang digunakan pada robot 6WD ini menentukan pergerakan dari robot. Tidak hanya sensor jarak yang dapat mengendalikan robot, tapi sensor gas juga dapat mengendalikan pergerakan robot. Jika terjadi kebocoran yang terdeteksi oleh sensor gas dan terbaca nilai ADC diatas 200, maka robot 6WD akan secara otomatis berhenti. Jika tidak terjadi kebocoran atau gas buthana hanya terdeteksi sebentar, maka robot akan melanjutkan kembali perjalanannya hingga menemukan kebocoran gas buthana. Gambar 19 merupakan keadaan robot 6WD saat mendeteksi adanya kebocoran gas dan terlihat seluruh roda tidak bergerak. Led berwarna biru menandakan sensor gas mendeteksi kebocoran gas dengan nilai ADC diatas 200.

Selain dari pergerakan robot, pengiriman informasi perjalanan saat robot 6WD menelusuri lorong sangat diperlukanan karena robot tidak dapat dijangkau oleh pengelihatan pengguna. Untuk memastikan bahwa data yang

I Made Arya Budhana: Rancang Bangun Robot 6WD...

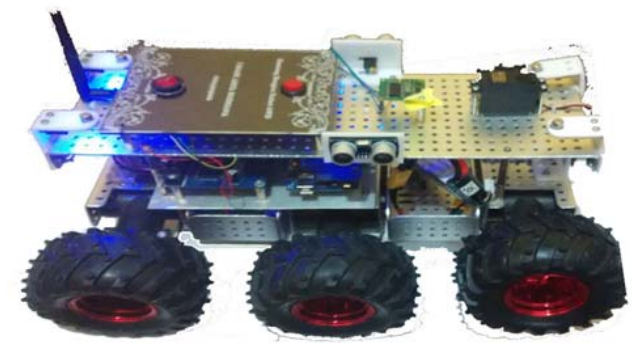

Gambar 18: Robot Mendeteksi kebocoran Gas Bhutana

dikirimkan oleh robot akurat dan real time dilakukan pengujian pengiriman informasi perjalanan ini. Selain berupa data - data angka, pada GCS juga dilakukan pengolaha data informasi robot 6WD, yaitu berupa indikator saat terjadi kebocoran gas dan penunjuk arah. Hal ini dilakukan agar pengguna dapat lebih cepat mencerna informasi yang dikirim oleh robot 6WD dan dapat segera melakukan tindakan. Gambar 19 merupakan tampilan GCS saat menerima informasi dari robot 6WD.

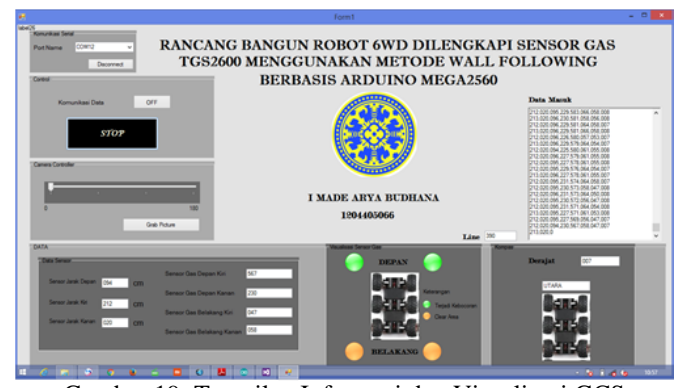

Gambar 19: Tampilan Informasi dan Visualisasi GCS

Pada Gambar 20 terlihat bahwa terjadi kebocoran di 2 titik, yaitu pada bagian depan kiri dan depan kanan robot. Jika diamati lebih detail, maka terlihat bagian depan kiri mendeteksi kebocoran gas lebih besar dibandingkan bagian depan kanan. Informasi ini dapat dilihat pada Gambar 21 yang menyajikan data secara rinci yang diterima oleh sensor gas.

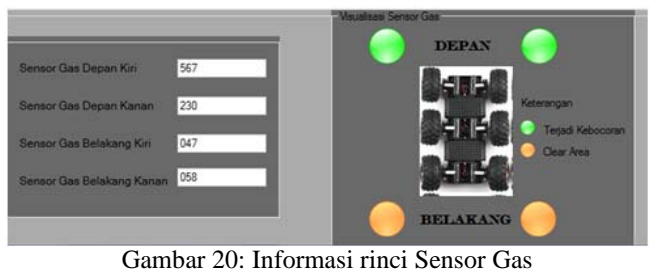

Pada GCS juga terdapat beberapa informasi tambahan berupa arah dari robot 6WD serta jarak yang terukur dari sisi kanan, kiri dan depan robot. Gambar 20 menunjukan bahwa robot sedang melakukan perjalanan menuju arah utara.

\section{KESIMPULAN}

Simpulan yang dapat diambil berdasarkan hasil pengujian dan pembahasan yang telah dilakukan adalah :

1. Robot 6WD dilengkapi sensor gas TGS2600 menggunakan metode wall following telah berhasil dibuat. Metode wall following dengan menggunakan

p-ISSN:1693 - 2951; e-ISSN: 2503-2372 
sensor srf HC-SR04 pada robot 6WD untuk menelusuri dinding telah berhasil, namun masih terdapat kelemahan pada sistem ini karena tidak menggunakan kontroller untuk mengatur kecepatan dari motor dc yang ada pada robot 6WD. Saat robot mendeteksi adanya kebocoran gas, maka dengan sendirinya robot 6WD berhenti untuk mengamati lebih lama dan mengambil gambar kejadian yang tidak dapat dicapai oleh pengelihatan pengguna. Informasi - informasi yang didapat oleh robot 6WD telah berhasil dikirim dan divisualisasikan oleh GCS agar pengguna dapat mengetahui jika terjadi kebocoran gas dengan cepat tanpa harus membandingkan data yang ada pada GCS.

2. Sensor jarak dengan tipe HC-SR04 memiliki tingkat akurasi buruk untuk mengukur jarak objek yang berada terlalu dekat, namun untuk jarak $2 \mathrm{~cm}$ akurasi dari sensor ini cukup akurat.

3. Penggunaan Radio HMTRP dengan frekuensi $433 \mathrm{MHz}$ memerlukan antena tambahan untuk mencapai jarak pancar yang lebih jauh.

\section{REFERENSI}

[1] M.I. Triyandana, Abdul Muid, T. Rismawan, "Pendeteksi Gas LPG dengan Sensor TGS 2610 dan Sensor Gas TGS 2611 Berbasis
Mikrokontroler ATmega 328P,” Jurnal Coding Universitas Tanjungpura, Vol. 03, pp.11 - 21, 2015.

[2] Istadi, D. (2013) Chemical Engineering. [online]. Available: http://tekim.undip.ac.id/staf/istadi/files/2013/09/01-introductionnatural-gas-processing .pdf/

[3] I.B.A. Swamardika, I.N. Budiastra, I.N. Setiawan, Yogi Hendrayanto, I.P.A.M. Pratama, "Rancang Bangun Robot 6WD Sebagai Alat Pendeteksi Kebocoran Gas CO dan Bhutana Berbasis Komunikasi Wireless Xbee Pro Series $160 \mathrm{~mW}$,”Jurnal Teknik Elektro Universitas Udayana, pp. 52-57, 2015.

[4] “TGS2600 data sheet," Figaro, USA.

[5] F.Z. Rachman, Nur Yanti, "Robot Penjejak Ruangan dengan Sensor Ultrasonik dan Kendali Ganda Melalui Bluetooth,” Jurnal Elektronika Terpadu Politeknik Negeri Balikpapan, Vol.4, pp. 114 - 119, Oktober.

[6] “SRF HC-SR04 data sheet,” Elec Freaks, China.

[7] Ari Begnarly, Hendy Wicaksono, "Pengaplikasian TPA81 dan CMPS03 Pada Rancang Bangun Robot Beroda KRPAI 2013,” Jurnal Ilmiah Mahasiswa Universitas Surabaya, Vol. 2, 2013.

[8] Sukindar (2016) Kelebihan Bahasa Pemrograman C\#. [online]. Available: https://teknojurnal.com/kelebihan-bahasa-pemrograman-csharp/

[9] As'Ari. "Perancangan Robot Wall Follower dengan Metode Proportional Integral Derivative (PID) Berbasis Mikrokontroller," Universitas Andalas. 2013.

[10] Fahmizal (2013) Robot Wall Follower. [Online]. Available: https://fahmizaleeits.wordpress.com/ 2012/09/30/robot-wall-followerdengan-kendali-pid/ 